\title{
Kinetic study on electrochemical oxidation of catechols in the presence of cycloheptylamine and aniline: Experiments and digital simulation
}

\author{
DAVOOD NEMATOLLAHI ${ }^{\mathrm{a}, *}$, FATEMEH GHASEMI ${ }^{\mathrm{a}}$, SADEGH KHAZALPOUR ${ }^{\mathrm{a}}$ and \\ FAHIMEH VARMAGHANI ${ }^{\mathrm{b}, \mathrm{c}}$ \\ ${ }^{a}$ Faculty of Chemistry, Bu-Ali Sina University, 65178-38683, Hamedan, Iran. \\ ${ }^{b}$ Department of Chemistry, Institute for Advanced Studies in Basic Sciences (IASBS), Zanjan, Iran \\ ${ }^{\mathrm{c}}$ Center for Research in Basic Sciences and Contemporary Technologies, IASBS, Zanjan, Iran \\ e-mail: nemat@basu.ac.ir
}

MS received 2 August 2016; revised 7 October 2016; accepted 14 October 2016

\begin{abstract}
Oxidative coupling reaction of some catechols has been studied by cyclic voltammetry at the glassy carbon electrode in different experimental conditions. The electrogenerated $o$-banzoquinone participates in a coupling reaction with anionic and dianionic forms of catechol. Based on $E C$ mechanism, the observed homogenous rate constants of the coupling reaction of catechols were estimated by analyzing the cyclic voltammetric responses using the simulation software DIGIELCH. This paper deals with reaction of $o$-benzoquinones derived by the oxidation of catechol (CAT), 3-methylcatechol (3-MC), 3-methoxycatechol (3-MOC) and 3,4-dihydroxybenzoic acid (3,4-DHBA) with cycloheptylamine (a primary aliphatic amine) and aniline (a primary aromatic amine) as nucleophiles to gain mechanistic insight. The outcome indicates participation of $o$-benzoquinone in the Michael addition reaction with the studied primary amines. The best fit of the experimental and simulated results was obtained for ECE mechanism. The calculated/estimated homogeneous rate constants $\left(k_{\mathrm{obs}}\right)$ for $\mathrm{Michael}$ addition reaction were found to vary in the order $\mathbf{C A T}>\mathbf{3}-\mathbf{M C}>\mathbf{3}-\mathbf{M O C}>\mathbf{3 , 4}$ DHBA and CAT > 3,4-DHBA > 3-MC > 3-MOC for cycloheptylamine and aniline, respectively. These data are in agreement with the trend of electronic properties (electron-donating/-withdrawing) of the substitutions on the catechol ring.
\end{abstract}

Keywords. Catechol; cyclic voltammetry; cycloheptylamine; aniline; coupling reaction; digital simulation.

\section{Introduction}

Catechol as a nature-based molecule has been given the attention for use as drugs. Comprehensive medicinal chemistry (CMC) database introduced 78 catecholic drugs. ${ }^{1}$ Antioxidative properties of catecholic compounds are well known for their ability to protect against reactive oxidative species. ${ }^{2-4}$ Some pharmacological effects of catecholic drugs are adrenergic (isoproterenol, epinephrine, dopamine), antioxidant (gossypol, baicalein), antiasthmatic ((r)-isoproterenol, levisoprenaline), antibiotic (cefetecol, fomidacillin), enzyme inhibitor (benserazide, carbidopa) ${ }^{1}$ and anticancer activities. ${ }^{5}$ Catechols can be easily oxidized electrochemically to $o$-benzoquinones at low oxidation potentials in mild media. ${ }^{6}$ Based on many evidences, $o$-benzoquinone undergoes a coupling reaction with anionic and dianionic species of catechol to form $\mathrm{C}-\mathrm{C}$ or $\mathrm{C}-\mathrm{O}$ bond. ${ }^{7-9}$

Quinone, a quite reactive molecule, acts as Michael acceptor to react with various nucleophilic compounds.

\footnotetext{
*For correspondence
}

Electrochemically induced Michael addition reaction of $o$-benzoquinones with some primary ${ }^{10,11}$ and secondary ${ }^{12-14}$ amines has been investigated. Herein, to get more insight into the oxidative coupling of catechols, we have investigated the electrochemical oxidation of catechols in absence and presence of cycloheptylamine (1) as a primary aliphatic amine and aniline (2) (a primary aromatic amine). The paper has evaluated mechanistic and kinetic behavior of anodically generated quinones in the presence of $\mathbf{1}$ and $\mathbf{2}$ and the observed homogeneous rate constant $\left(k_{\text {obs }}\right)$ values of the reaction of $o$-benzoquinones with these nucleophiles were estimated by digital simulation of the corresponding cyclic voltammograms at various experimental conditions such as $\mathrm{pH}$, potential scan rate and nucleophile concentration.

\section{Experimental}

\subsection{Apparatus and Reagents}

Cyclic voltammetry was performed using Sama-500 instrument. The working electrode used in the voltammetry 
experiments was a glassy carbon disk $(1.8 \mathrm{~mm}$ diameter), and platinum wire was used as counter electrode. The working electrode potential was measured vs. SCE. Before recording each voltammogram, the working electrode was carefully cleaned by polishing with alumina slurry and finally washed with distilled water. A Metrohm-pH meter was used for $\mathrm{pH}$ measurements. A mixture of $\mathrm{Na}_{2} \mathrm{CO}_{3} / \mathrm{NaHCO}_{3}$ was used as buffer for $\mathrm{pH} 8-10$. Phosphate was utilized to provide $\mathrm{pH}$ of 2, 3, 6 and 7, and acetate buffer for $\mathrm{pH}$ 4 and 5. The total concentration of the buffer species was adjusted to $0.2 \mathrm{M}$. The homogeneous rate constants were estimated by analyzing the cyclic voltammetric responses using the simulation software DIGIELCH. ${ }^{15}$ Catechol and its derivatives (3-methylcatechol (3-MC), 3-methoxycatechol (3MO), 3,4-dihydroxybenzoic acid (3,4-DHBA), 2,3-dihydroxybenzoic acid (2,3DHBA)) and other chemicals were procured from E. Merck. All solutions in voltammetric studies were deoxygenated by bubbling pure nitrogen.

\section{Results and Discussion}

Initially, electrochemical performance of catechol was analyzed by cyclic voltammetry in acidic, neutral and basic solutions. Figure 1 demonstrates $\mathrm{pH}$ dependence of the cyclic voltammogram. The cyclic voltammograms show one anodic $\left(\mathrm{A}_{1}\right)$ and a corresponding cathodic peak $\left(\mathrm{C}_{1}\right)$. Catechol undergoes an oxidative electron transfer and converts into $o$-benzoquinone and vice versa in a two-electron process.

In acidic media, the current ratio $\left(I_{\mathrm{pC} 1} / I_{\mathrm{pA} 1}\right)$ is nearly unity. By increasing $\mathrm{pH}$, the peak current ratio deviates from unity and approaches to zero in basic solution. This behavior is related to the coupling of anionic and dianionic forms of catechol with $o$-benzoquinone. ${ }^{7-9}$

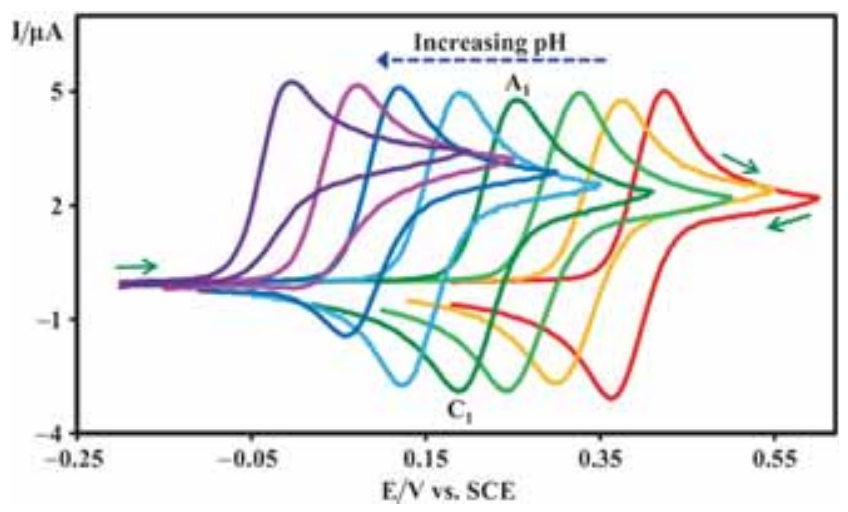

Figure 1. Cyclic voltammograms of catechol $(1.0 \mathrm{mM})$ at glassy carbon electrode, in water (at various $\mathrm{pH}$ values of 2.0, 3.0, 4.0, 5.0, 6.0, 7.0, 8.0, and 9.0, respectively)/ethanol $(70: 30, \mathrm{v} / \mathrm{v})$ mixture. Scan rate: $10 \mathrm{mV} \mathrm{s}^{-1}$. Temperature $=$ $25 \pm 1^{\circ} \mathrm{C}$.
Acid dissociation reaction causes the anionic form of catechol and the ratio of anionic/neutral forms increases along with increasing $\mathrm{pH}$.

The electrochemical oxidation of catechol was studied in various concentrations. Figure 2 shows the normalized cyclic voltammograms of catechol at different concentrations. The normalized voltammograms were made by dividing the current by concentration $(I / c$ vs. $\left.\mu \mathrm{A} \mathrm{mM}^{-1}\right)$. As can be seen, the peak current ratio $\left(I_{\mathrm{pC} 1} / I_{\mathrm{pA} 1}\right)$ is not constant and is dependent on the concentration of catechol. This implies the coupling reaction after electron transfer process. The higher is the concentration of catechol, the less is cathodic peak current.

The effect of coupling reaction on the cyclic voltammograms was analyzed by digital simulation and homogeneous rate constants $\left(k_{\mathrm{obs}}\right)$ of the coupling reaction of $o$-benzoquinones with catechol derivatives were estimated. The simulation was carried out assuming semiinfinite one-dimensional diffusion and planar electrode geometry. A reversible two-electron transfer process was defined. The heterogeneous rate constant $(0.002 \mathrm{~cm} / \mathrm{s})$ for oxidation of catechols was estimated by use of experimental working curves. ${ }^{16}$ The formal potentials were obtained experimentally as the midpoint potential between the anodic and cathodic peaks $\left(E_{\mathrm{mid}}\right)$. The transfer coefficient $(\alpha)$ was assumed 0.5 . When entering $\alpha$, the charge transfer is treated to obey the ButlerVolmer equation. An irreversible second-order chemical reaction was defined in the dialog box of the software. This chemical reaction was characterized by equilibrium constant $\left(K_{\text {eq }}\right)$, forward $\left(k_{f}=k_{\text {obs }}\right)$ and backward ( $k_{\mathrm{b}}, k_{\mathrm{b}}$ equals to zero for irreversible process) rate constant. Some other experimental parameters entered

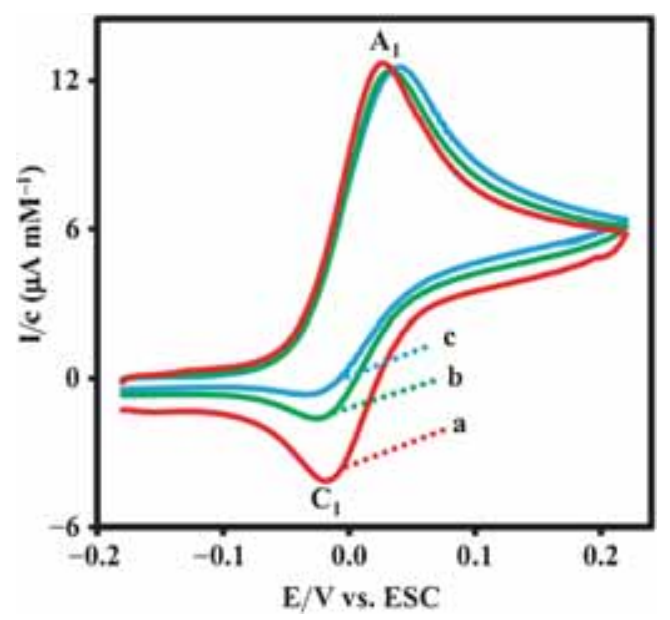

Figure 2. Cyclic voltammograms of a) $0.5 \mathrm{mM}$, b) $1.0 \mathrm{mM}$ and c) $2.0 \mathrm{mM}$ catechol at glassy carbon electrode in water (carbonate buffer, $c=0.2 \mathrm{M}, \mathrm{pH} 8.5) /$ ethanol $(70: 30, \mathrm{v} / \mathrm{v}$ ) mixture at scan rate $=100 \mathrm{mV} \mathrm{s}^{-1}$. Temperature $=25 \pm 1^{\circ} \mathrm{C}$. 
for digital simulation consisted of the following: $E_{\text {start }}$, $E_{\text {switch, }} E_{\text {end }}, T=25^{\circ} \mathrm{C}$, potential scan rate, surface area of electrode $(1.8 \mathrm{~mm}$ diameter $)$ and the analytical concentration of catechol. All parameters were kept constant throughout the fitting of the digitally simulated voltammogram to the experimental data. The parameter $k_{\text {obs }}$ was allowed to change through the fitting process. The simulation was performed based on $E C$ mechanism ( $E$ : electrochemical oxidation of catechol and $C$ : coupling reaction of catechol with $O$ benzoquinone) (Scheme 1) (Figure 3). The calculated rate constant values of the coupling reaction of catechol (CAT), 3-methylcatechol (3-MC), 3-methoxycatechol (3-MOC), 3,4-dihydroxybenzoic acid (3,4-DHBA) and 2,3-dihydroxybenzoic acid (2,3-DHBA) for various $\mathrm{pH}$ values are given in Table 1.

It is apparent from the Table 1 that $\mathrm{pH}$ of solution and nature of the substituted group on the catechol ring affect the coupling reaction rate. The reactivity for catechols varies in the following order: CAT $>$ 2,3-DHBA $>$ 3-MC $>$ 3,4-DHBA $>$ 3-MOC. The observed trends are attributed to electron-donating character and position of substituted groups. The presence of an

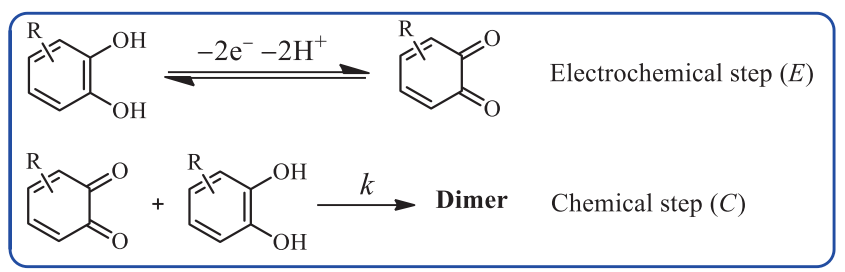

Scheme 1. Proposed mechanism for the oxidative coupling of catechol derivatives.
Table 1. Calculated/estimated homogeneous rate constants $\left(k_{\mathrm{obs}}\right)$ for the oxidative coupling reaction of catechols $(1.0 \mathrm{mM})$ in water/ethanol $(70: 30, \mathrm{v} / \mathrm{v})$ mixture at various $\mathrm{pH}$ values.

\begin{tabular}{lccc}
\hline & \multicolumn{3}{c}{$k_{\mathrm{obs}}\left(\mathrm{M}^{-1} \mathrm{~s}^{-1}\right)$} \\
\cline { 2 - 4 } Catechol & $\mathrm{pH}=8.0$ & $\mathrm{pH}=9.0$ & $\mathrm{pH}=10.0$ \\
\hline CAT & $4875( \pm 150)^{\mathrm{a}}$ & $8925( \pm 95)^{\mathrm{a}}$ & $14066( \pm 200)^{\mathrm{a}}$ \\
2,3DHBA & $3020( \pm 83)$ & $6175( \pm 100)$ & $11000( \pm 70)$ \\
3-MC & $1050( \pm 86)$ & $4080( \pm 57)$ & $8675( \pm 95)$ \\
3,4-DHBA & $500( \pm 10)$ & $1850( \pm 91)$ & $6666( \pm 81)$ \\
3-MOC & $198( \pm 8)$ & $950( \pm 35)$ & $3050( \pm 130)$ \\
\hline
\end{tabular}

${ }^{\text {a }}$ for $n=5$ at various scan rates.

electron-donating group of $\mathrm{CH}_{3}, \mathrm{OCH}_{3}$ or $\mathrm{COO}^{-}$on the produced $o$-quinone ring makes it more difficult to participate in the coupling reaction. In addition, the presence of carboxylate group in C-4 position of $\mathbf{3 , 4 - D H B A}$ which is a reactive site of 3,4-dihydroxybenzoquinone toward coupling reaction, causes a decrease in the homogeneous rate constant. On the other hand, the presence of an electron-donating group in the catechol ring makes the nucleophile stronger, so that the Michael addition is favored. So, the presence of an electrondonating group in the molecule ring has two different effects. It increases the nucleophilicity of the catechol, while decreasing the electrophilicity of $o$-benzoquinoe toward the Michael addition reaction. However, our data show that, its effect on the decreasing of the electrophilicity of $o$-benzoquinone is more than the increase of the nucleophilicity of catechol.

Figure 4 shows the voltammetric responses of catechol $(1.0 \mathrm{mM})$ in the presence of cycloheptylamine

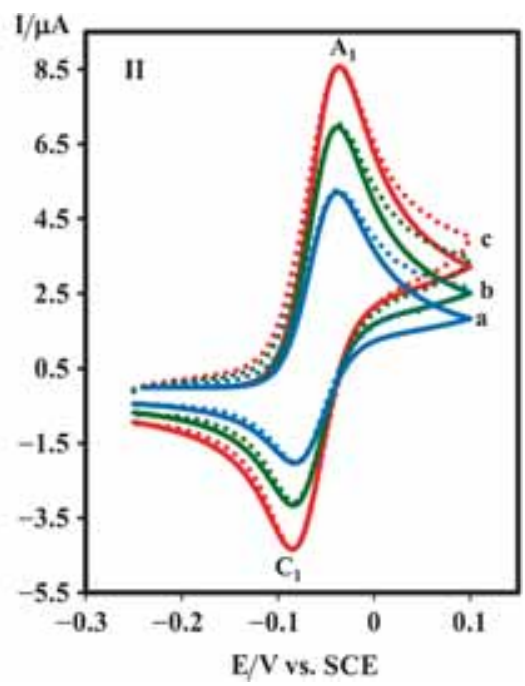

Figure 3. Experimental (...) and simulated (- ) cyclic voltammograms (1.0 mM) of: (I) 2,3DHBA at scan rates $100,150,250 \mathrm{mV} \mathrm{s}^{-1}$ and (II) 3-MC at scan rates $40,60,80 \mathrm{mV} \mathrm{s}^{-1}$ in water (carbonate buffer, $c=0.2 \mathrm{M}, \mathrm{pH}$ $8.5) /$ ethanol $(70: 30, \mathrm{v} / \mathrm{v})$ mixture. Temperature $=25 \pm 1^{\circ} \mathrm{C}$. 


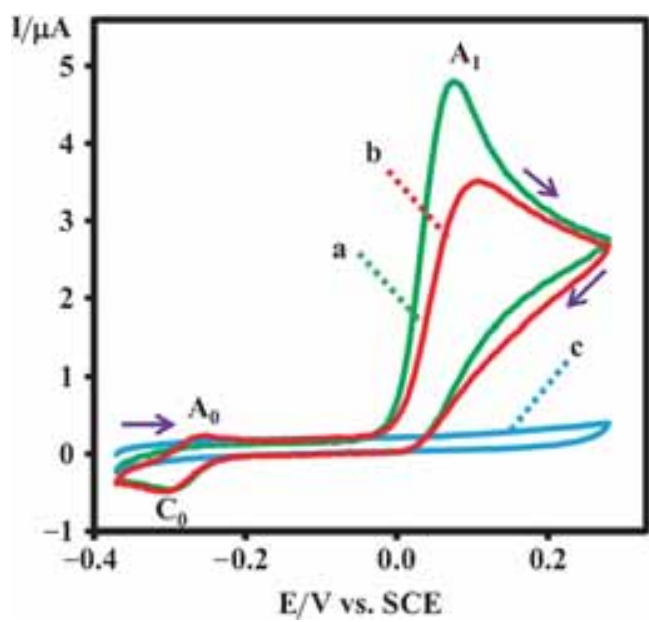

Figure 4. First (a) and second (b) cyclic voltammograms of catechol $(1.0 \mathrm{mM})$ in the presence of cycloheptylamine (1) $(1.0 \mathrm{mM})$; (c) cyclic voltammogram of cycloheptylamine $\mathbf{1}$ in the absence of catechol, at glassy carbon electrode, in water (carbonate buffer, $c=0.2 \mathrm{M}, \mathrm{pH} 8.5$ )/ethanol (70:30, v/v) mixture. Scan rate: $10 \mathrm{mV} \mathrm{s}^{-1}$. Temperature $=25 \pm 1^{\circ} \mathrm{C}$.

(1) $(1.0 \mathrm{mM})$. Curve 'a' indicates the first cycle of voltammogram obtained for solution of catechol in the presence of cycloheptylamine in water (carbonate buffer, $c=0.2 \mathrm{M}, \mathrm{pH} 8.5) /$ ethanol (70:30, v/v) mixture. The cathodic peak $\mathrm{C}_{1}$ vanishes in comparison with voltammogram of catechol in the absence of $\mathbf{1}$ and a new cathodic peak $\mathrm{C}_{0}$ appears at a more negative potential, $-0.32 \mathrm{~V}$ vs. SCE. Disappearance of $\mathrm{C}_{1}$ peak in the reverse scan indicates the oxidation process followed by a chemical reaction that rapidly removed generated $o$-benzoquinone from the electrode surface. A new anodic peak $\left(\mathrm{A}_{0}\right)$ and its counterpart $\left(\mathrm{C}_{0}\right)$, appears in the second cycle (curve 'b') with an $E_{\mathrm{p}}$ value of $-0.32 \mathrm{~V}$ (vs. SCE). This new redox couple $\left(\mathrm{A}_{0} / \mathrm{C}_{0}\right)$ is attributed to the oxidation and reduction of the adduct formed from the reaction of $o$-benzoquinone with cycloheptylamine. The voltammogram of cycloheptylamine $\mathbf{1}$ (curve 'c') shows this species is electro-inactive in the defined potential window.

More detailed evidence on the occurrence of chemical reaction coupled with electron transfer process was obtained by cyclic voltammetry at various scan rates, varying from 10 to $250 \mathrm{mV} \mathrm{s}^{-1}$. Figure 5 compares the cyclic voltammograms of catechol in the presence of 1 at different scan rates. Two considerable changes are observed by decreasing time window of the experiment (increasing scan rate). The first is increasing of the peak current ratio, $I_{\mathrm{pC} 1} / I_{\mathrm{pA} 1}$ and the second is decreasing of $I_{\mathrm{pC} 0} / I_{\mathrm{pC} 1}$. At high scan rates the extent of the reaction between $o$-benzoquinone and $\mathbf{1}$, and consequently, the amount of product at the electrode surface that causes a cathodic peak current $\left(\mathrm{C}_{0}\right)$ decreases. $I_{\mathrm{pA} 1} / I_{\mathrm{pC} 1}$ and

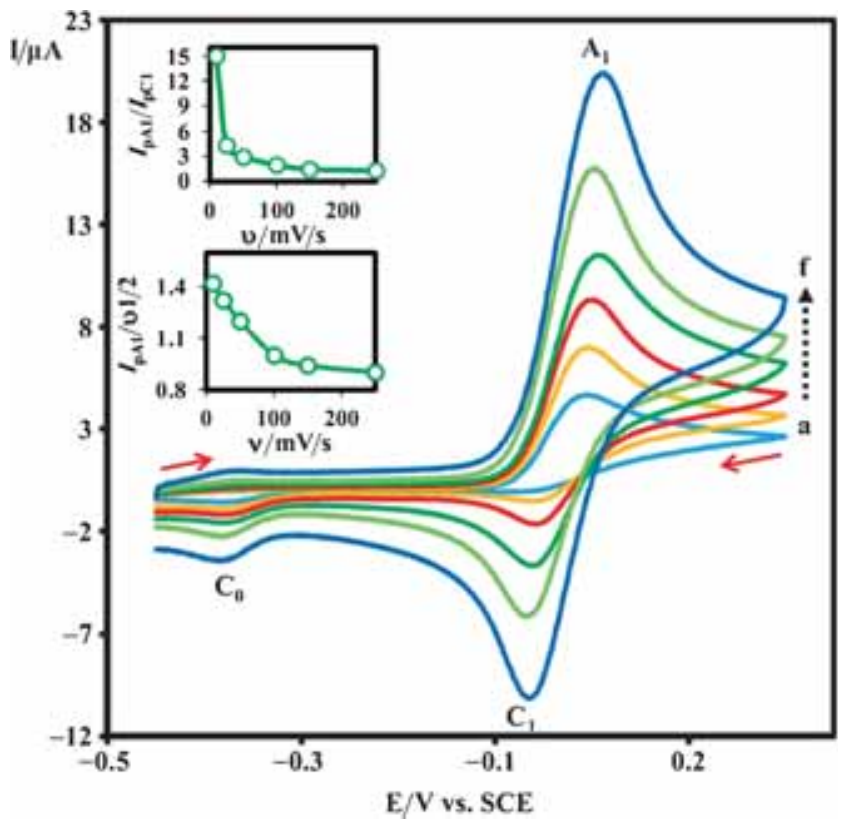

Figure 5. Typical voltammograms of catechol $(1.0 \mathrm{mM})$ in the presence of cycloheptylamine $(\mathbf{1})(5.0 \mathrm{mM})$ at a glassy carbon electrode, in water (carbonate buffer, $c=0.2 \mathrm{M}, \mathrm{pH}$ $8.5) /$ ethanol $(70: 30, \mathrm{v} / \mathrm{v})$ mixture at various scan rates. Scan rates from a) to d) are $10,25,50,100,150$ and $250 \mathrm{mV} \mathrm{s}^{-1}$. Temperature $=25 \pm 1{ }^{\circ} \mathrm{C}$. Inset: variation of peak current ratio $\left(I_{\mathrm{pAl}} / I_{\mathrm{pC} 1}\right)$ and peak current function $\left(I_{\mathrm{pAl}} / v^{1 / 2}\right)$ vs. scan rate.

$I_{\mathrm{pA} 1} / v^{1 / 2}$ are expressed vs. scan rate (Figure 5, inset). The appearance of peak $\mathrm{C}_{0}$, on the one hand, and decrease of the current function $I_{\mathrm{pA} 1} / v^{1 / 2}$ and $I_{\mathrm{pA} 1} / I_{\mathrm{pC} 1}$ ratio with increasing scan rate, on the other hand, stand in conformity with $E C E$ mechanism.

To gain more information, influence of the concentration of cycloheptylamine (1) on the oxidation of catechol was studied. As shown in Figure $6, I_{\mathrm{pC} 0} / I_{\mathrm{pC} 1}$ increases with increase in the concentration of 1 . Peak $\mathrm{C}_{0}$ and its counterpart one $\left(\mathrm{A}_{0}\right)$ are connected with reduction and oxidation of adduct formed by the reaction of $o$-benzoquinone with 1 . The chemical reaction is more favorable at higher concentration of $\mathbf{1}$.

The cyclic voltammetry data, in keeping with our previous reports on the electrochemical oxidation of catechols in the presence of nucleophiles containing amine groups ${ }^{10-14}$ indicate that the electrogenerated $o$-benzoquinone in the presence of cycloheptylamine (1) converts to 1a via Michael addition reaction. The better electron-donating group in 1a makes it easier to undergo oxidation than the starting species (Scheme 2). So, the redox peak $\left(\mathrm{A}_{0} / \mathrm{C}_{0}\right)$ presented in Figure 4 is attributed to the oxidation and reduction of $\mathbf{1 a}$ and $\mathbf{1} \mathbf{a}^{\prime}$, respectively.

Digital simulation was used to gain more mechanistic insight of the electrochemical oxidation of catechol 

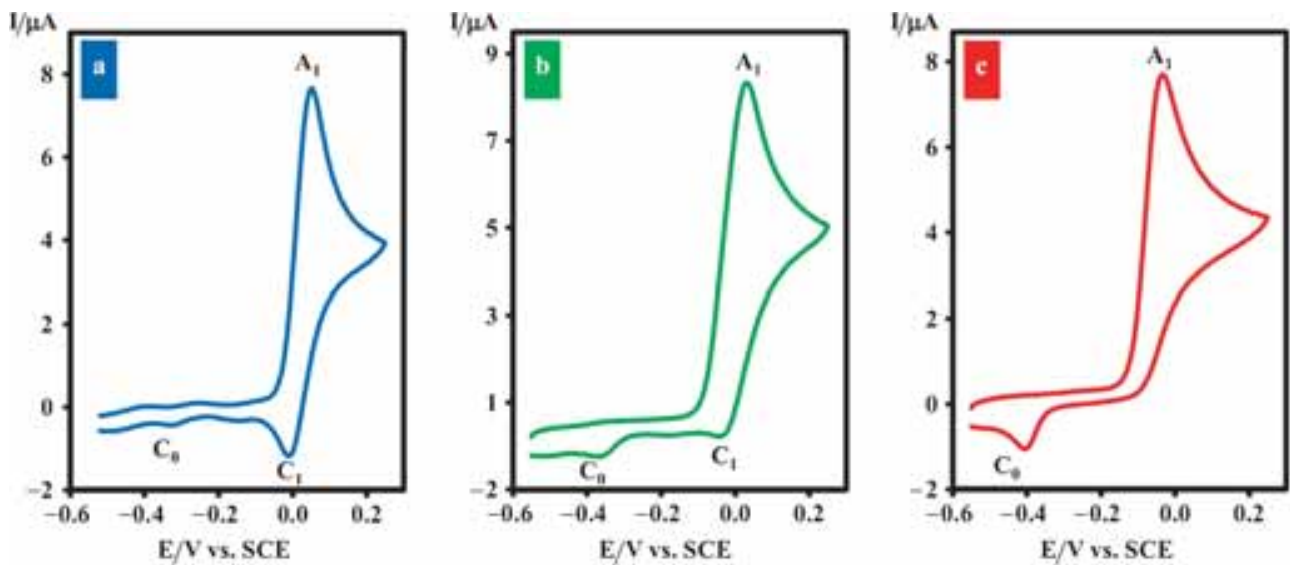

Figure 6. Typical voltammograms of catechol $(1.0 \mathrm{mM})$ in the presence of a) $1.0 \mathrm{~b}) 3.0$ and c) $5.0 \mathrm{mM}$ of cycloheptylamine (1) at a glassy carbon electrode, in water (carbonate buffer, $c=0.2 \mathrm{M}, \mathrm{pH} 8.5) /$ ethanol (70:30, v/v) mixture. Scan rate $25 \mathrm{mV} \mathrm{s}^{-1}$. Temperature $=25 \pm 1{ }^{\circ} \mathrm{C}$.

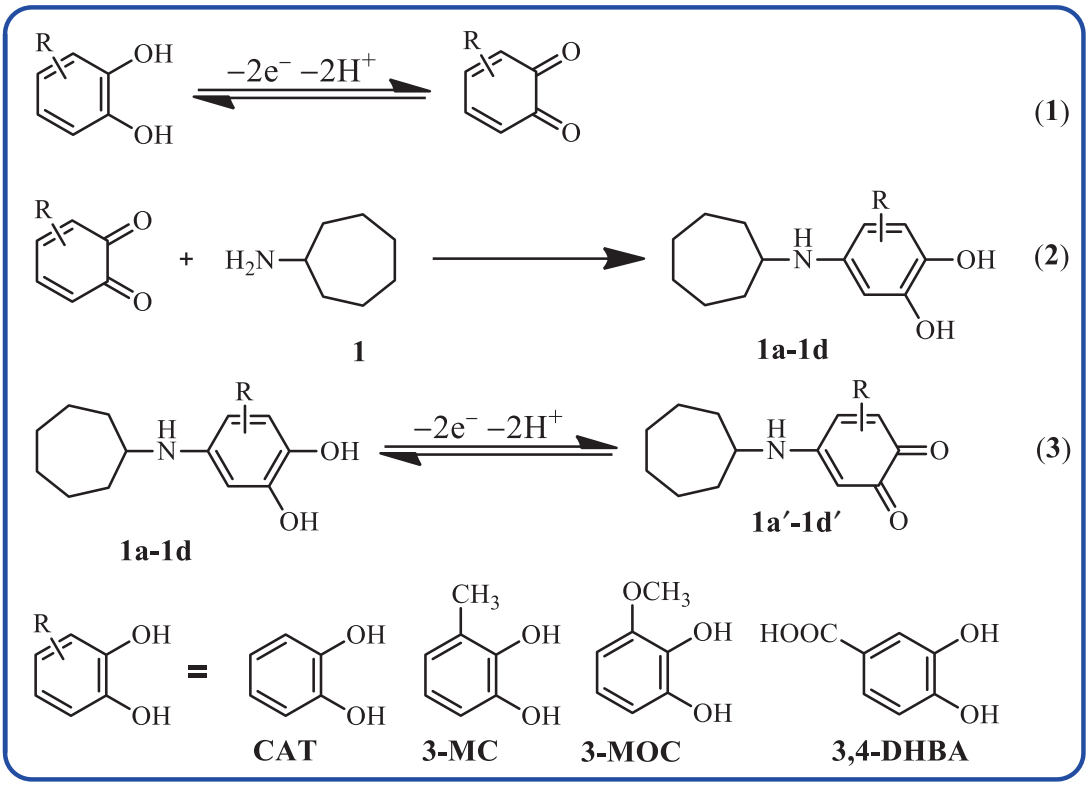

Scheme 2. Proposed mechanism for the electrochemical oxidation of catechol derivatives in the presence of cycloheptylamine (1).

derivatives in the presence of cycloheptylamine (1). The best fits of the experimental and simulated voltammograms were obtained by $E C E$ mechanism under secondorder conditions (Figure 7). The calculated/estimated homogeneous rate constants $\left(k_{\mathrm{obs}}\right)$ of Michael addition reaction of cycloheptylamine to $o$-benzoquinone derivatives at different $\mathrm{pH}$ values are represented in Figure 8. As is expected, $k_{\mathrm{obs}}$ increases with increasing $\mathrm{pH}$. It is due to the protonation of amine group of cycloheptylamine and its inactivation toward Michael reaction at lower $\mathrm{pH}$ values.

In addition, the magnitude of observed homogeneous rate constants is in agreement with the trend of the electronic properties of the substituents. The electron-donating groups such as methyl, methoxy and carboxylate ion on the catechol ring were found to make Michael addition reaction difficult. The order of the calculated/estimated homogeneous rate constant is as follows: CAT $>$ 3-MC $>$ 3-MOC $>$ 3,4-DHBA. The least value of $k_{\text {obs }}$ belongs to $\mathbf{3 , 4 - D H B A}$. This behavior is due to the electron-donating character of carboxylate ion on the one hand, and occupation of one reaction site by this group, on the other hand.

Voltammetric studies of catechols were also performed in the presence of aniline as an aromatic primary amine. Figure 9 shows the cyclic voltammograms 

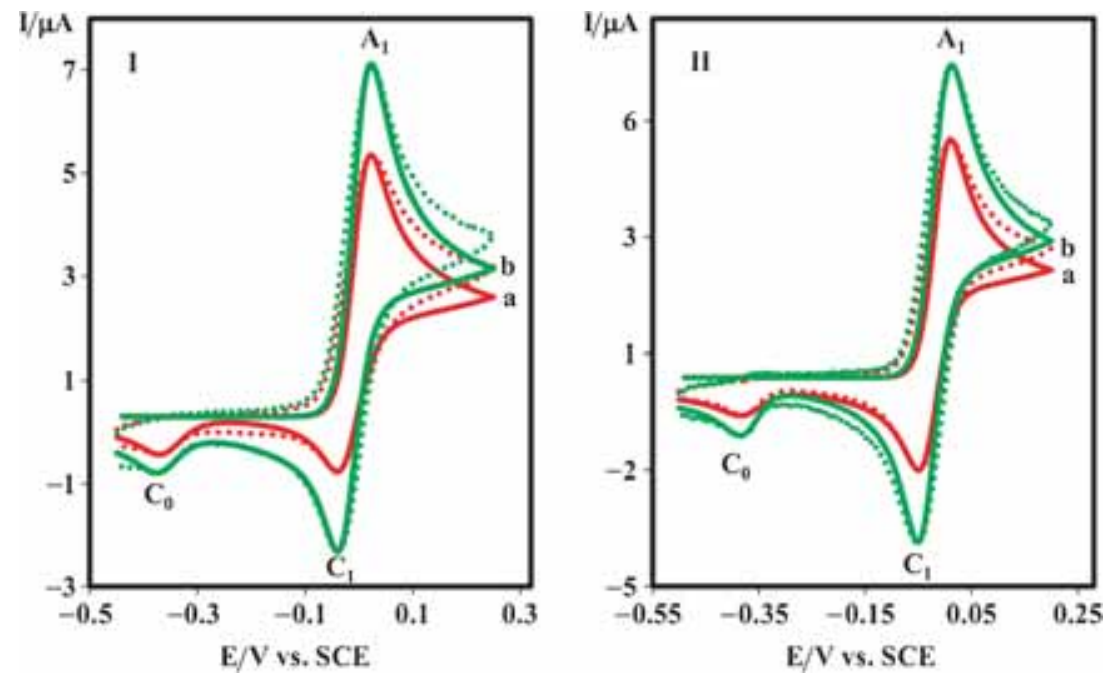

Figure 7. Experimental (...) and simulated (--) cyclic voltammograms of $1.0 \mathrm{mM}$ (I) 3-MC and (II) 3-MOC in the presence of cycloheptylamine (1) (3.0 mM) in water (carbonate buffer, $c=0.2 \mathrm{M}, \mathrm{pH} 8.5) /$ ethanol $(70: 30, \mathrm{v} / \mathrm{v})$ mixture at scan rates a) 20 and b) $40 \mathrm{mVs}^{-1}$, Temperature $=25 \pm 1^{\circ} \mathrm{C}$.

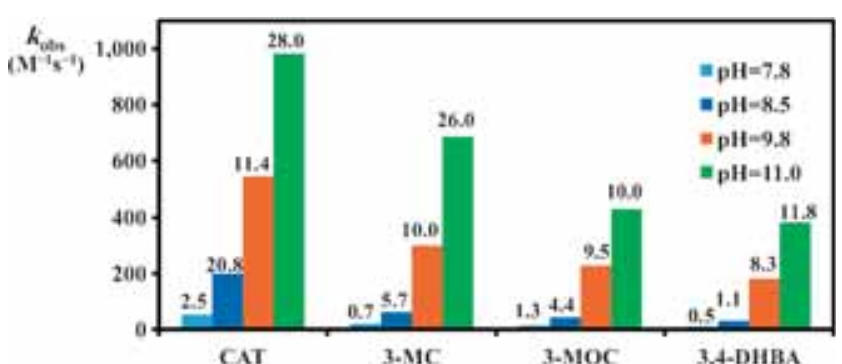

Figure 8. Calculated/estimated homogeneous rate constants $\left(k_{\text {obs }}\right)$ for Michael addition reaction of cycloheptylamine (1) with catechol derivatives for different $\mathrm{pH}$ values with the same cncentration. The numbers on the columns indicate the standard deviation that are calculated by five independent simulations at various scan rates.

of catechol $(1.0 \mathrm{mM})$ in the presence of aniline (2) $(1.0 \mathrm{mM})$ at various potential sweep rates. In comparison with cycloheptylamine (1), almost the same voltammetric behavior was observed in electrochemical oxidation of catechol in the presence of aniline (2). However, although, aniline is less basic than cycloheptylamine, ${ }^{17}$ it seems to have a higher reaction rate in comparison with cycloheptylamine.

Compared to aniline, cycloheptylamine is inactive toward $o$-benzoquinone in acidic media. This is connected with more protonation of cycloheptylamine compared with aniline and consequently, more inactivation towards the Michael addition reaction with $o$-benzoquinone. The results also show that proportional to the increasing of the potential sweep rate, the cathodic peak $\mathrm{C}_{1}$ appears and the height of it increases. The increasing the peak current ratio $I_{\mathrm{pC} 1} / I_{\mathrm{pC} 0}$

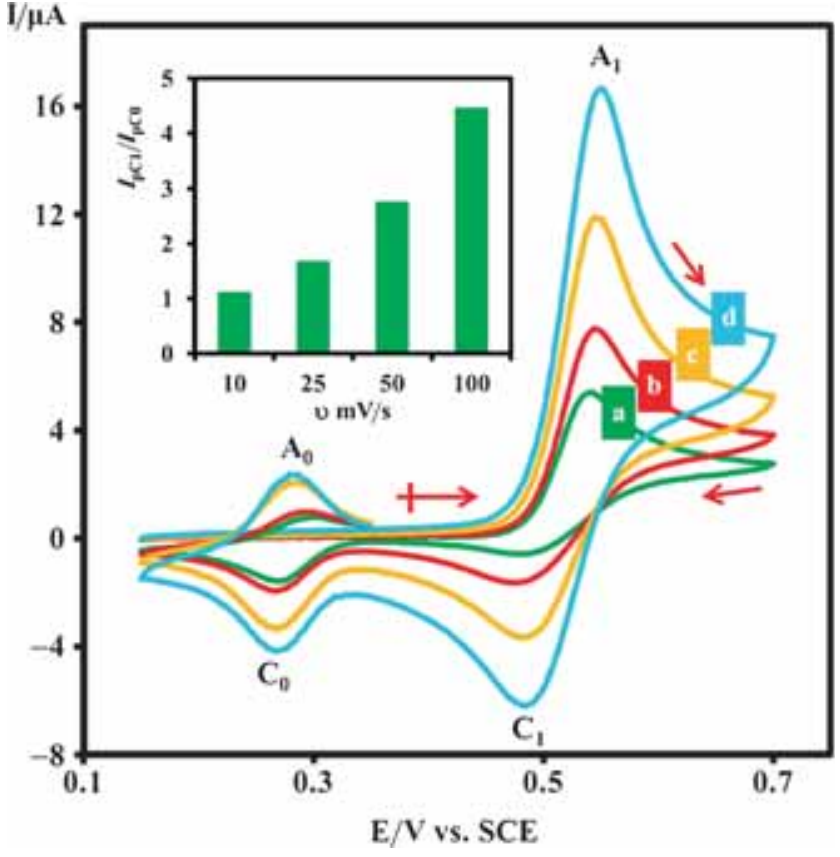

Figure 9. First and second cycle of voltammograms of catechol $(1.0 \mathrm{mM})$ in the presence of aniline $(2)(1.0 \mathrm{mM})$ at a glassy carbon electrode, in aqueous perchloric acid $(0.1 \mathrm{M})$ at different scan rates. Scan rates from a) to d) are 10, 25, 50 and $100 \mathrm{mV} \mathrm{s}^{-1}$. Temperature $=25 \pm 1{ }^{\circ} \mathrm{C}$. Inset: Variation of peak current ratio $\left(I_{\mathrm{pC} 1} / I_{\mathrm{pC} 0}\right)$ vs. scan rate.

(Figure 9, inset) by augmentation of potential sweep rate is an indication of a chemical reaction after electron transfer process.

More studies were performed by varying $\mathrm{pH}$ of solution. Cyclic voltammograms of catechol $(1.0 \mathrm{mM})$ in the presence of $2(1.0 \mathrm{mM})$ in the $\mathrm{pH}$ range of $1-3$ are shown in Figure 10. The height of the cathodic peaks $C_{1}$ 


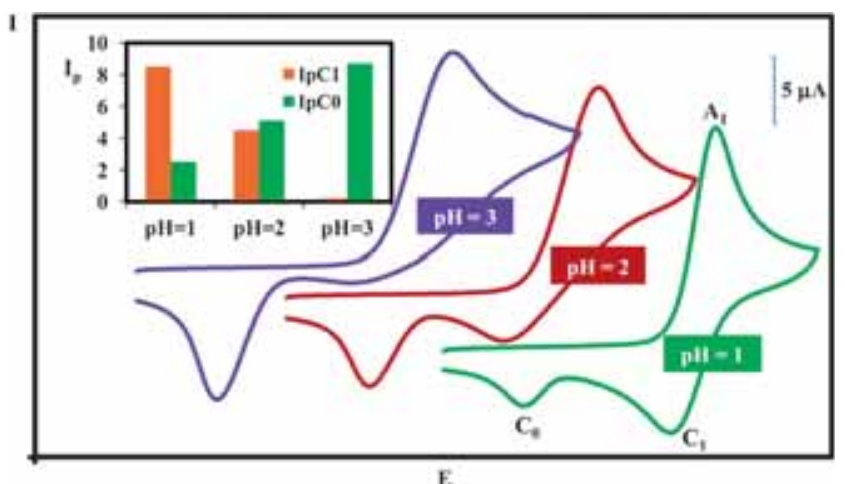

Figure 10. Cyclic voltammograms of $1.0 \mathrm{mM}$ catechol in the presence of $1.0 \mathrm{mM}$ aniline (2) at a glassy carbon electrode, in water/ethanol (70/30) solution containing $0.1 \mathrm{M}$ perchloric acid (for $\mathrm{pH}=1.0$ ) and $0.2 \mathrm{M}$ phosphate buffer solution with $\mathrm{pH}=2.0$ and 3.0. Scan rate: $100 \mathrm{mV} \mathrm{s}^{-1}$. Temperature $=25 \pm 1^{\circ} \mathrm{C}$.

and $\mathrm{C}_{0}$ is strongly dependent on the $\mathrm{pH} . I_{\mathrm{pC} 1}$ decreases and finally disappears with increasing $\mathrm{pH}$, while under these conditions, $I_{\mathrm{pC} 0}$ increases. In other words, the rate of the reaction of $\mathbf{2}$ with $o$-benzoquinone increases with increasing $\mathrm{pH}$.

As discussed before, the nucleophilicity of aniline decreases with decreasing $\mathrm{pH}$ (protonation of amine group). In order to carry out a more detailed analysis, electrochemical oxidation of catechols in the presence of $\mathbf{2}$ was tested by digital simulation in the studied $\mathrm{pH}$ range. The simulation was performed based on ECE mechanism (Scheme 3). In ECE mechanism, the peak current ratio of $I_{\mathrm{pCl}} / I_{\mathrm{pA} 1}$, and $I_{\mathrm{pCl}} / I_{\mathrm{pC} 0}$ can be considered as criteria for the chemical reaction (Michael addition) rate. The observed homogeneous rate constants of Michael addition reaction at different $\mathrm{pH}$ values are reported in Table 2.
Table 2. Calculated/estimated homogeneous rate constants $\left(k_{\mathrm{obs}}\right)$ for the Michael addition reaction of $o$ benzoquinones with aniline (2) in the $\mathrm{pH}$ range of 2-4 at the same concentration.

\begin{tabular}{lccc}
\hline & \multicolumn{3}{c}{$k_{\mathrm{obs}}\left(\mathrm{M}^{-1} \mathrm{~s}^{-1}\right)$} \\
\cline { 2 - 4 } Catechols & $\mathrm{pH}=2.0$ & $\mathrm{pH}=3.0$ & $\mathrm{pH}=4.0$ \\
\hline CAT & $507( \pm 15)^{\mathrm{a}}$ & $4000( \pm 100)^{\mathrm{a}}$ & $16000( \pm 350)^{\mathrm{a}}$ \\
$3-\mathrm{MC}$ & $92( \pm 5)$ & $618( \pm 41)$ & $6233( \pm 251)$ \\
$3,4-D H B A$ & $340( \pm 14)$ & $1280( \pm 28)$ & $9000( \pm 353)$ \\
3-MOC & $53( \pm 7.6)$ & $314( \pm 13.4)$ & $2625( \pm 95)$ \\
\hline
\end{tabular}

${ }^{\text {a }}$ for $n=5$ at various scan rates.

According to Scheme 3, the dependency of $k_{\mathrm{obs}}$ on $\mathrm{pH}$ is consistent with the following equation:

$$
k_{\mathrm{obs}}=\alpha k
$$

where $k$ is homogeneous rate constant of Michael addition reaction when $100 \%$ of the aniline (or cycloheptylamine) is in its neutral form and $\alpha$ is the fraction of the aniline in the neutral form $\left(\mathrm{C}_{6} \mathrm{H}_{5}-\mathrm{NH}_{2}\right)$, as defined below:

$$
\alpha=\mathrm{K}_{\mathrm{a}} /\left(K_{\mathrm{a}}+\left[H^{+}\right]\right)
$$

where $\mathrm{K}_{\mathrm{a}}$ is the acid dissociation constant of anilinium ion $\left(\mathrm{C}_{6} \mathrm{H}_{5}-\mathrm{NH}_{3}^{+}\right)$. As deduced from equation (2), $\alpha$ decreases with decreasing $\mathrm{pH}$, and thus decreasing $k_{\text {obs }}$. On the other hand, aliphatic amines are much stronger bases than aromatic amines. Protonated cycloheptylamine has a $\mathrm{pK}_{\mathrm{a}}$ value of about 9.99 as compared with 4.60 for aniline. ${ }^{17}$ The calculated $\alpha_{\text {cycloheptylamine }}$ and $\alpha_{\text {aniline }}$ at the same $\mathrm{pH}$ (for example, at $\mathrm{pH}=2.0$ ) are $1.26 \times 10^{-8}$ and $2.51 \times 10^{-3}$, respectively. These data confirm the higher reaction rate of aniline compared to cycloheptylamine.

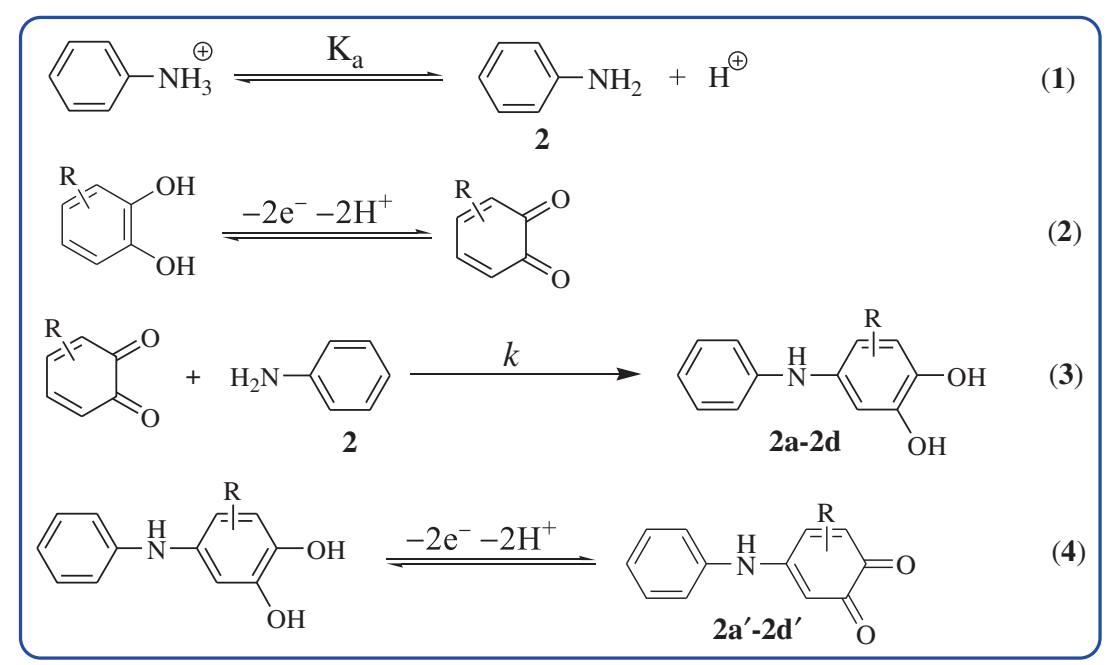

Scheme 3. The reaction mechanism for the electrochemical oxidation of catechols in the presence of aniline (2). 


\section{Conclusions}

The electrochemical oxidation of some catechol derivatives was investigated. Based on many evidences, ${ }^{7-9}$ electrogenerated $o$-benzoquinone undergoes a coupling reaction with anionic and dianionic forms of catechol to form of $\mathrm{C}-\mathrm{C}$ or $\mathrm{C}-\mathrm{O}$ bond. The rate of coupling reaction of $o$-benzoquinones is prominently different and depends on their concentration, structures and $\mathrm{pH}$ of the solution. On the other hand, the electrochemically generated $o$-benzoquinone as a Michael acceptor will react with nucleophiles stronger than catechol. ${ }^{18-31}$ Our data shows that the electrochemical oxidation pathway of catechol in the presence of nucleophiles depends on the nature of the nucleophile. When the nucleophile has electron-withdrawing character like $\mathrm{NO}_{2}^{-},{ }^{19}$ $\mathrm{CN}^{-},{ }^{20}$ arylsulfinic acids, ${ }^{21}$ triphenylphosphine, ${ }^{22}$ and mercaptobenzoxazole, ${ }^{23}$ the oxidation of the product is more difficult than the oxidation of catechol and consequently, the oxidation of the product is circumvented under the controlled potential electrolysis. Under these conditions, the oxidation pathway of catechol is EC. However, when the nucleophiles have electron-donating properties like amines, ${ }^{12,24,25}$ indole derivatives, ${ }^{26,27}$ azide ion $^{28}$ and $\beta$-diketones, ${ }^{29-31}$ the oxidation of the product is easier than the oxidation of catechol and thus, the adduct formed between catechol and nucleophile becomes re-oxidized and therefore, the oxidation pathway is ECE. In this work, the reaction of electrochemically generated $o$-benzoquinones with cycloheptylamine (1) and aniline (2) has been studied using cyclic voltammetry. The kinetics of the mentioned reactions (coupling reaction of $o$-benzoquinones with catechols and the Michael addition reaction of $o$-benzoquinones with $\mathbf{1}$ and 2) are studied by the simulation of the experimental voltammograms under $E C$ and ECE mechanisms, respectively. The effects of $\mathrm{pH}$ and substituted group of the catechols on the observed homogeneous rate constant $\left(k_{\mathrm{obs}}\right)$ have been discussed.

\section{Acknowledgments}

Authors acknowledge Bu-Ali Sina University Research Council and Center of Excellence in Development of Environmentally Friendly Methods for Chemical Synthesis (CEDEFMCS) for their support of this work.

\section{References}

1. Yang D P, Ji H F, Tang G Y, Ren W and Zhang H Y 2007 Molecules 12878
2. Tejero I, Gonzalez-García N, Gonzalez-Lafont A and Lluch J 2007 J. Am. Chem. Soc. 1295846

3. Justino G C, Correia C F, Mira L, Borges Dos Santos R M, Martinho Simões J A, Silva A M, Santos C and Gigante B 2006 J. Agric. Food Chem. 54342

4. Bernini R, Crisante F, Barontini M, Tofani D, Balducci V and Gambacorta A 2012 J. Agric. Food Chem. 607408

5. Ali A, Bansal D, Kaushik N K, Kaushik N, Choi E H and Gupta R 2014 J. Chem. Sci. 1261091

6. Nematollahi D, Rafiee M and Fotouhi L 2009 J. Iran. Chem. Soc. 6448

7. Rayn M D, Yueh A and Chen W Y 1980 J. Electrochem. Soc. 1271489

8. Nematollahi D, Rafiee M and Samadi-Meybodi A 2004 Electrochim. Acta 492495

9. Stum D I and Suslov S N 1979 Biofizika 2140

10. Salehzadeh H, Nematollahi D and Hesari H 2013 Green Chem. 152441

11. Nematollahi D, Feyzi-Barnaji B, Salehzadeh H and Varmaghani F 2014 J. Electrochem. Soc. 161 G33

12. Nematollahi D, Tammari E, Sharifi S and Kazemi M 2004 Electrochim. Acta 49591

13. Habibi D, Nematollahi D and Azimi S 2008 Tetrahedron Lett. 495043

14. Nematollahi D and Hesari M 2005 J. Electroanal. Chem. 577197

15. Rudolph M 2004 J. Electroanal. Chem. 571289

16. Greef R, Peat R, Peter L M, Pletcher D and Robinson J 1990 In Instrumental Methods in Electrochemistry (New York: Ellis Horwood Limited) p. 189

17. Patai S 1968 In The Chemistry of the Amino Group (London: John Wiley \& Sons)

18. Nematollahi D and Shayani-jam H 2008 J. Org. Chem. 733428

19. Salahifar E, Nematollahi D, Mahyari A and Nosratzadegan K 2015 J. Electrochem. Soc. 162 G19

20. Nematollahi D, Alimoradi M and Waqif Husain S 2004 Electroanalysis 161359

21. Nematollahi D and Rahchamani R 2002 Tetrahedron Lett. 43147

22. Nematollahi D, Tammari E and Esmaili R $2008 \mathrm{~J}$. Electroanal. Chem. 621113

23. Nematollahi D and Tammari E 2005 J. Org. Chem. 707769

24. Kiani A, Raoof J B, Nematollahi D and Ojani R 2005 Electroanalysis 171755

25. Raoof J B, Ojani R, Nematollahi D and Kiani A 2009 Int. J. Electrochem. Sci. 4810

26. Nematollahi D and Hedayatfar V 2011 J. Chem. Sci. 123709

27. Nematollahi D and Dehdashtian S 2008 Tetrahedron Lett. 49645

28. Nematollahi D, Afkhami A, Tammari E, Shariatmanesh T, Hesari M and Shojaeifard M 2007 Chem. Commun. 162

29. Nematollahi D and Goodarzi H 2002 J. Org. Chem. 675036

30. Nematollahi D and Rafiee M 2005 Green Chem. 7638

31. Nematollahi D, Habibi D, Rahmati $M$ and Rafiee $M$ 2004 J. Org. Chem. 692637 